\title{
Analysis of Simulation Outputs for the Mutual Effect of Flow in Weir and Gate System
}

\author{
Sarhan Abdulsatar Sarhan \\ Shaker Abdulatif Jalil \\ Water Resources Engineering Department, College of Engineering, University of \\ Duhok, Iraq
}

sarhan.abdulsatar@uod.ac

shaker.abdulatif@uod.ac

\begin{abstract}
The problem of suspended material and its deposition can be reduced by the combined system of weir and gate flow. Simulating this system aims to understand and analyse the mutual effect of them. Experimental work has been carried out to validate models of the combined system. Vertical sharp edges of gate and weir are tested by changing four times gate opening. The simulations base on RNG k$\varepsilon$ turbulence model and a comparison between flow surface profile and discharge has been done and they showed acceptable reliability. The investigation indicats that two flow portions separate at different levels depending on upstream depth and this separation level falls to reach halve of the distance between system edges as the depth increases. The relative weir to gate discharge increases from 0.4 up to 1.8 as gate opening decreases $60 \%$. As total depth of flow upstream $(\mathrm{H})$ increases by $46 \%$, the discharge of gate increase $5 \%, 7 \%, 12 \%, 26 \%$ for gate opening of $2,3,4,5 \mathrm{~cm}$ respectively, while the weir dischage increase about 5 times. The Weir in combined system performs better by $5 \%$ to $20 \%$ as compared with the conventional one. Within the study limitations, two mathematical models are suggested to predict discharge of weir in a system and for the gate with acceptable coefficient of determination.
\end{abstract}

Keywords: Combined system, Weir flow; Gate flow; Flow portions; Gate opening.

\section{INTRODUCTION}

The deposition problem of materials in front of conventional weir can be overcomed by opening a gate beneath weir. This combined system has two flow characteristics; accordingly, investigators have studied properties of such flow combination. Modelling of flow over sharp weir and validation has been carried on by numerous investigations. A good agreement had found between simulation of weir flow and carried a comparison of flow properties such as pressure head, distribution of velocity, and water surface profiles with that of experimental data by employing k$\varepsilon$ turbulence model [1]. Following the method of Zhao and Tai for finite volume numerical hybrid level discretizations, Lv et al. [2] were able to study the flow over sharp and broad weirs for validation of that numerical schemes. Lv et.al model shows a good quantitative agreement and can visualise time development of vortices motions. Numerical model has been employed by Rady [3] using the Flow-3D package to find the coefficient of discharge for sharp crested weir, the validation based on earlier empirical values found by Sarginson, Raju and Asawa which shows a good agreement. Simulation of scour pool behind wier has been done by Liu and Bai [4] who employ k-E tarbulance model built in ANSYS Fluent 6.3 package. The simulation shows a very good quantitative outcome which deals with hydraulics theoretical analysis. A wide Numerical Simulation of flow over a semi cylinder weir inwhich six different turbulence models have been employed and validaty comparison has been done with experimantal measured velocity and flow profile by Akoz et al. [5]. This comprehenseve study concludes that Reynolds stress turbulence model provides better consequence for horizontal velocity. The classical k-e 
turbulence model has been employed for simulating submerged flow over weirs which shows good agreement with the measured field velocity [6]. Another modeling meshless method has been employed to simulate flow under gate, this method based on natural element interpolation which first introduced by Sibso [7]. The natural element method shows good agreement with pressure distributions of gate flow [8]. Two experimental studies on weir with bottom opening [9] and [10] show that the conveyance efficiency of weir's has been increased in transport water to downstream part of channel, the better performance depends on shape and number of openings. Sadrabadi and moghaddam [11] has been simulated the flow passing triangular porous weirs with constant porosity and constant height. Six different side slopes physical models were been tested, the results showed a good agreement between them. The flow profile was show by RNG K-e turbulence model and the best weir performance was the weir of 60-degree side slope. Experimental investigations on the combined system flow over weir and under gate were carried out by Altan-Sakarya and Kökpinar [12] and Khassaf \& Habeeb [13].These studies based on data regression analysis and then they proposed mathematical relationships to predict discharge passing such shapes of hydraulic structures. Samani \& Mazaheri [14] used hydraulic principles of continuity and energy conservation to propose mathematical models for predicting stage-discharge relationship for the combined system flow of weir and gate in two cases of submargence. The proposed mathematical models are validated in the data of the experimental. There was a good agreement between them. Modelling by employing ANSYS Fluent package for the combined flow of sharp edges for each weir and gate, and experimental validity was been carried by Arvanaghi, H. and Mahtabi [15]. The study showed that there is approximately linear relationship between the coefficient of discharge and the flow depth upstream and the maximum value of the coefficient is 0.66. Analysis was carried by Parsaie et al [16] on available experimental data for the combined flow system pass cylindrical structure. The analysis based on two intelligent systems methods. The first one is neuro fuzzy inference network and the second is multilayer perceptron neural network for predicting coefficient of discharge. The two methodes showed pridiction ability and the first one has the advantage. This study aims to modelling the combined flow system using commercial Flow-3D package by both validating the model with experimental physical measures carried out in the laboratory and finding the mutual effect role of the two parts of flow.

\section{Theoretical Background}

A good basic background on the weir and gate flow theory can be cited in many original literatures such as Henderson [17], Chow [18] and Subramanya [19]. Empirical formula have been introduced for estimating the flow discharge over a sharp weir such as well-known Rehbock formula, equation (1)

$$
Q=\frac{2}{3}\left(0.611+0.08 \frac{h}{P}\right) \sqrt{2 g} B h^{3 / 2} \ldots \ldots \ldots \ldots
$$

Free and submerged Flow under gates has been investigated and empirical formulas have been suggested. For submerged flow, the above original literatures have good theoretical explanation more over the practical study of Lozano et al. [20] with wide empirical reviews of literature find that coefficient of discharge $\left(\mathrm{C}_{d}\right)$ as a parabolic function of the gate opening, $d$. The discharge equation (2) is: 
$\mathrm{Q}=\mathrm{C}_{\mathrm{d}} \times \mathrm{d} \times \mathrm{B} \sqrt{2 \mathrm{~g} \cdot \Delta \mathrm{H}}$

Where $\mathrm{B}$ is the width of channel and $\Delta \mathrm{H}$ is the depth difference between upstream and downstream. The free flow behind sluice gate is a rapidly varied flow. The free surface profile of flow has a curvature shape. The generation of the surface profile is affected by the geometric boundary such as gate opening (d), gate lip shape, depth of flow upstream $(\mathrm{H})$, angle of inclination and bed roughness which are the major factors affecting the contraction of flow (see above original literatures). Equation (3) presents the discharge of free flow.

$\mathrm{Q}=\mathrm{C}_{\mathrm{d}} \times \mathrm{d} \times \mathrm{B} \sqrt{2 \mathrm{~g} \cdot \mathrm{H}}$

where $\mathrm{H}$ is the depth upstream and $\mathrm{C}_{\mathrm{d}}$ is a function of contraction coefficient which is within the range of 0.60-0.65 by Defina and Susin [21].

Early in the eighteenth century theoretical equations describing fluid flow were derived. Euler equations for non-viscous fluid flow which describe the relation between velocity, pressure and density are coupled differential equations for modelling ideal fluid motion. The extensions of the Euler equations which include the effect of internal shear forces are known as Navier-Stokes equations (France and England scientists), these equations describe real fluids motion based on conservation of mass and momentum including viscous property of fluids, and they are presented in equation (4) and (5).

$\frac{\partial}{\partial x_{i}}\left(\rho U_{i}\right)=0$

$\frac{\partial\left(\rho U_{i}\right)}{\partial t}+\frac{\partial}{\partial x_{j}}\left(\rho U_{i} U_{j}-\tau_{i j}\right)+\frac{\partial P}{\partial x_{i}}-S_{M}=0$

Where $\rho$ is fluid density, $\mathrm{U}$ is the velocity, $\tau$ is molecular stress tensor, $\mathrm{P}$ is the pressure and $S_{M}$ is source term. The aim of solving these equations is to describe the systems behavior of fluid flow near to real flow by simulation. Turbulent flow generates when the ratio of inertial forces to viscous forces increases. In this state of flow, random fluctuations of velocity happened. The solution of this situation based on Reynolds decomposition that use mean steady value of velocity [22]. Substitution of the value of the sum of means in stade of velocity vector in conservation equations leads to the flowing equations (6 and 7).

$\frac{\partial}{\partial x_{i}}\left(\rho \bar{U}_{i}\right)=0$

$\frac{\partial}{\partial x_{j}}\left(\rho \bar{U}_{i} \bar{U}_{j}-\bar{\tau}_{i j}\right)+\frac{\partial \bar{P}}{\partial x_{i}}-\bar{S}_{M}=\frac{\partial}{\partial x_{j}}\left(-\rho \bar{u}_{\imath} \bar{u}_{J}\right)$

Where $\tau_{i j}=\left[\mu\left(\frac{\partial U_{i}}{\partial x_{j}}+\frac{\partial U_{j}}{\partial x_{i}}\right)\right] \quad$ is a term of molecular stress and the term $\frac{\partial}{\partial x_{j}}\left(-\rho \bar{u}_{\imath} \bar{u}_{j}\right)$ is Reynolds stress represents shearing deformations. And according to [22], the numerical model of solution depends on the number of extra stress terms included in algorithm. Finally, the model of the momentum equation has been presented in literature, as it is show in equation ( $8 \mathrm{a}$ and $8 b$ ). 


$$
\begin{aligned}
\frac{\partial(\rho k)}{\partial t}+\operatorname{div}(\rho k U) & =\operatorname{div}\left[\sigma_{k} \mu_{\text {eff }} \operatorname{grad} k\right]+2 \mu_{t} S_{i j} S_{i j}-\rho \varepsilon \ldots \ldots \ldots \ldots \ldots(8 a) \\
\frac{\partial(\rho \varepsilon)}{\partial t}+\operatorname{div}(\rho \varepsilon U) & =\operatorname{div}\left[\sigma_{k} \mu_{e f f} \operatorname{grad} \varepsilon\right]+C_{1 \varepsilon}^{*} \frac{\varepsilon}{k} 2 \mu_{t} S_{i j} S_{i j}-C_{2 k}^{*} \rho \frac{\varepsilon^{2}}{k} \ldots \ldots .(8 b) \\
\text { Where } \quad \mu_{t} & =\rho C_{\mu} \frac{k^{2}}{\varepsilon}, C_{1 \varepsilon}^{*}=C_{1 \varepsilon}-\frac{\eta\left(1-\frac{\eta}{\eta_{o}}\right)}{1+\beta \eta^{3}}, \quad \eta=\left(2 S_{i j} S_{j i}\right)^{1 / 2} \frac{k}{\varepsilon} \quad, \mathrm{k} \text { is the }
\end{aligned}
$$

turbulence kinetic energy and its rate of dissipation, $\varepsilon$. The symbol $\mu_{\mathrm{t}}$ is the turbulent or eddy-viscosity, While the adjustable constants for RNG $k-\varepsilon$ model are:

$C_{1 \varepsilon}=1.42 ; \quad C_{2 \varepsilon}=1.68 ; \quad C_{\mu}=0.0845 ; \quad \sigma_{k}=\sigma_{\varepsilon}=1.39 ; \quad \beta=0.012$ and $\eta_{o}=4.377$

The commercial software FLOW-3D includes five turbulence models, one of them is RNG $k$ - $\varepsilon$ turbulence models. This model is recommended to simulate a flow with chaos and unstable motion due to generation of eddies of various sizes Flow-3D [23]. Part of the total flow flows over weir and falls on the water which flows out of the gate and causes turbulence as it is shown in figure (1). Turbulent flow is a part of the domain under consideration. The turbulence model RNG ke- $\varepsilon$ is suitable for simulation. Figure (1) is a definition sketch representing Flow 3D output snap and parameters measured experimentally.

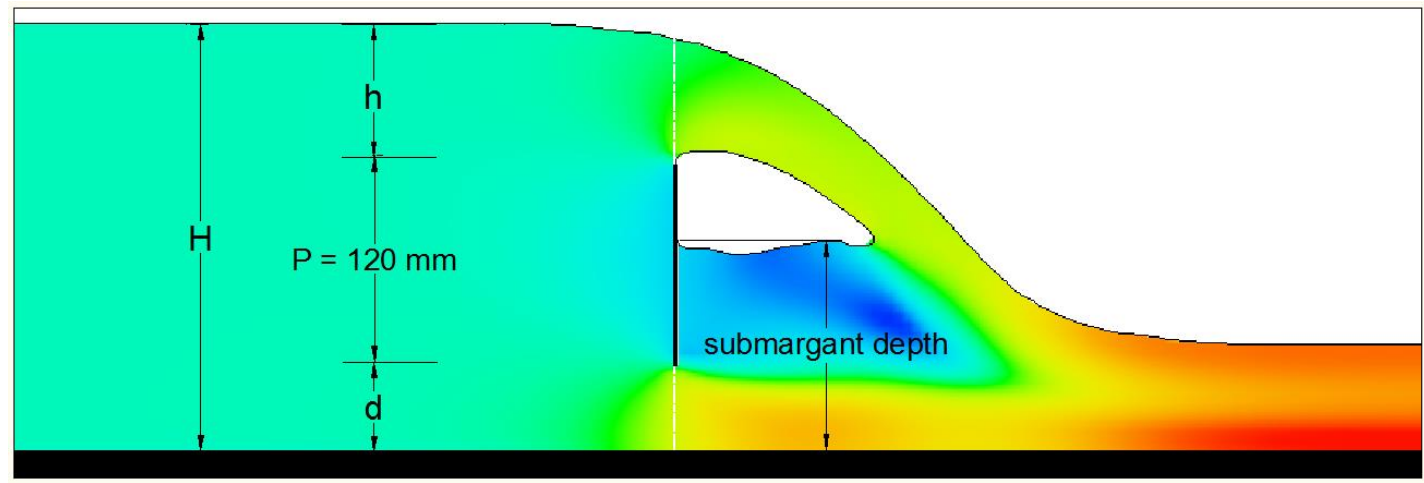

Figure (1): Flow-3D Snap with Definition Sketch

\section{Experimental and Numerical Model Validation}

The experimental work was carried out in $5 \mathrm{~m}$ horizontal rectangular flume of working length $5 \mathrm{~m}$; the width is $0.30 \mathrm{~m}$ and the depth is $0.40 \mathrm{~m}$. A plate of $0.006 \mathrm{~m}$ thickness of hard plastic was used to construct the combined weir and gate model of $0.12 \mathrm{~m}$ height. The upper and lower edges of the plate were sharpened to $0.002 \mathrm{~m}$ in order to construct a sharp weir and sharp gate. A point gauge with vernier scale of $0.1 * 10^{-3} \mathrm{~m}$ was used to measure the flow profile from the bed of the channel. The sharpened plate was connected to the channel side in a position that make the lower edge obove the bed by $0.02,0.03,0.04$ and $0.05 \mathrm{~m}$ which are the height of the gate way in this study.

FLOW-3D® software package has geometric tool which has been used to generate the weir and gate as a solid perpendicular to the direction of flow at a height from the bed equal to gate way. The same set-up has been applied to all simulations. The setup includes the selection of sharp interface, air entrainment, surface tension, gravitational acceleration in the vertical direction, viscous flow, 
turbulence model of Renormalized group turbulence model (RNG k- $\varepsilon$ ) and Nonslip wall shear boundary. According to the earlier studies the mish size which reflects discretization of computational domain has been set to $5 \mathrm{~mm}$ of aspect ratio which equals one. Domain boundary conditions have been chosen as wall for the two sides of channel and also for the bottom. The top of channel was symmetry, the upstream boundary condition was a pressure shose value is equal to flow depth, while the downstream was outflow. Two flux baffles were generated and placed over and under the plate to predict the flow discharge of each part of flow, while the third and the fourth flux Baffles were placed at the upstream and outlet to predict the total discharge. Two pressure velocity coupling solvers were built in FLOW-3D® package, their algorithms are based on semi-implicit numerical techniques, the first one is successive over relaxation (SOR) and the second is generalized minimum residual (GMRES ), the two solvers can predict fairly similar results as it is mensioned in the manual [23].

Verification of numerical model was based on three comparison of three different measures.The first comparison was the measured discharge and the total predicted discharge at upstream and outlet, the second one w between the measured discharge and the summation of predicted discharge of weir and gate, the third comparison was between the measured total head at upstream section and the predicted total head of the simulation output. Statistical analysis of homogeneity of samples and prediction percentage error were done to verify the numerical model. The T-test of the two samples was carried on SPSS-package with confidence 95\%. Table (1) shows the statistic descriptive of each two groups in each of the three comparison tests which include the mean, standard deviation and standard error. The values in each two sample groups are very close to each other in each of the three comparisons.

Table (1) Descriptive Statistics for Three Different Comparisons

\begin{tabular}{|cl|c|c|c|c|}
\hline \multicolumn{7}{|c|}{ Group Statistics } \\
\hline Group & & $\mathrm{N}$ & Mean & $\begin{array}{c}\text { Std. } \\
\text { Deviation }\end{array}$ & Std. Error Mean \\
\hline Total Discharge & 1 & 33 & 21.513333 & 5.7022127 & .9926278 \\
$(\mathrm{l} / \mathrm{s})$ & 2 & 33 & 21.392234 & 5.2618662 & .9159733 \\
\hline Q weir + Q gate & 1 & 33 & 21.513333 & 5.7022127 & .9926278 \\
$(\mathrm{l} / \mathrm{s})$ & 2 & 33 & 21.153217 & 5.1605767 & .8983411 \\
\hline Total Head $(\mathrm{cm})$ & 1 & 33 & 21.463636 & 1.7446271 & .3037006 \\
& 2 & 33 & 21.008974 & 1.7307018 & .3012765 \\
\hline
\end{tabular}

The homogeneity of sample groups are presented in table (2) which shows that the P-value of Levene's test is more than that 0.05 for all three comparison tests. This means that the variance of each two groups is the same. Moreover the P-value of 2tailed is also more than 0.05 , and there is no significant difference between the mean of the two groups. The zero value is in between the lower and upper difference. The results of this test show that the two sample groups of numerical and experimental are homogeneous. 
Journal of University of Babylon for Engineering Sciences, Vol. (26), No. (6): 2018.

Table (2) Independent T- test

\begin{tabular}{|c|c|c|c|c|c|c|c|c|c|c|}
\hline \multicolumn{11}{|c|}{ Independent Samples Test } \\
\hline & & \multicolumn{2}{|c|}{ Equality of Variances } & \multicolumn{7}{|c|}{ t-test for E qua lity of Means } \\
\hline & & \multirow[b]{2}{*}{$\mathrm{F}$} & \multirow[b]{2}{*}{ Sig. } & \multirow[b]{2}{*}{$\mathrm{t}$} & \multirow[b]{2}{*}{$d f$} & \multirow{2}{*}{$\begin{array}{l}\text { Sig. (2- } \\
\text { tailed) }\end{array}$} & \multirow{2}{*}{\begin{tabular}{c|} 
Mean \\
Difference
\end{tabular}} & \multirow{2}{*}{\begin{tabular}{l|} 
Std. Emor \\
Difference
\end{tabular}} & \multicolumn{2}{|c|}{ Difference } \\
\hline & & & & & & & & & Lower & Upper \\
\hline \multirow[t]{2}{*}{ Total D ischarge (Vs) } & $\begin{array}{l}\text { Equal variances } \\
\text { assumed }\end{array}$ & 283 & .597 & .090 & 64 & .929 & .1210989 & 1.3506728 & -2.5771803 & 2.8193781 \\
\hline & $\begin{array}{l}\text { Equal varian ces not } \\
\text { assumed }\end{array}$ & & & .090 & 63.591 & .929 & .1210989 & 1.3506728 & -2.5775146 & 2.8197123 \\
\hline \multirow[t]{2}{*}{$Q$ weir $+Q$ gate $(1 / s)$} & $\begin{array}{l}\text { Equal variances } \\
\text { assumed }\end{array}$ & 343 & .560 & 269 & 64 & .789 & .3601161 & 1.3387781 & -2.3144006 & 3.0346327 \\
\hline & $\begin{array}{l}\text { Equal variances not } \\
\text { assumed }\end{array}$ & & & 269 & 63.373 & .789 & .3601161 & 1.3387781 & -2.3149104 & 3.0351425 \\
\hline \multirow[t]{2}{*}{ Total Head $(\mathrm{cm})$} & $\begin{array}{l}\text { Equal variances } \\
\text { assumed }\end{array}$ & .015 & .904 & 1.063 & 64 & 292 & .4546622 & 4277869 & -3999403 & 1.3092646 \\
\hline & $\begin{array}{l}\text { Equal variances not } \\
\text { assumed }\end{array}$ & & & 1.063 & 63.996 & 292 & .4546622 & .4277869 & -3999414 & 1.3092657 \\
\hline
\end{tabular}

The prediction accuracy is measured by two well known statistical that are usually used to measure how close the predicted values to the real values are. They are Mean Absolute Percent Error (MAPE) and Root Mean Square Error (RMSE). The percentage of error tests shows in that are reasonable as presented in table (3).

Table (3) Percentage Error Test

\begin{tabular}{|lccc|}
\hline \multicolumn{1}{|c}{ Measure } & MAPE & RMSE & $\mathbf{R}^{\mathbf{2}}$ \\
\hline Discharge Q & 3.183367 & 0.870219 & 0.9839 \\
\hline $\mathrm{Q}_{\text {weir }}+\mathrm{Q}_{\text {gate }}$ & 3.250456 & 0.870219 & 0.9880 \\
\hline Total head upstreeam & 2.274396 & 0.529447 & 0.9751 \\
\hline
\end{tabular}

The measured surface water profile was compared with that predicted from all simulations. The comparison shows that the predicted surface profile tends to be a little bit lower than that of the measured one by $1.9 \%$.The calculated values of Mean Absolute Percent Error (MAPE) is equal to 2.331 and the Root Mean Square Error (RMSE) is equal to 0.288 . The overall comparison leads to accept simulation outputs for analysis.

\section{Results and Discussion}

The simulation outputs explains the related effect of weir flow on the gate flow. The simulation outputs show that for a constant gate opening (d) the flow upward direction increases when the depth of flow upstream increases. The results show that the upward flow direction reach to $\mathrm{P} / 2$ asit is shown in figrue (2). 


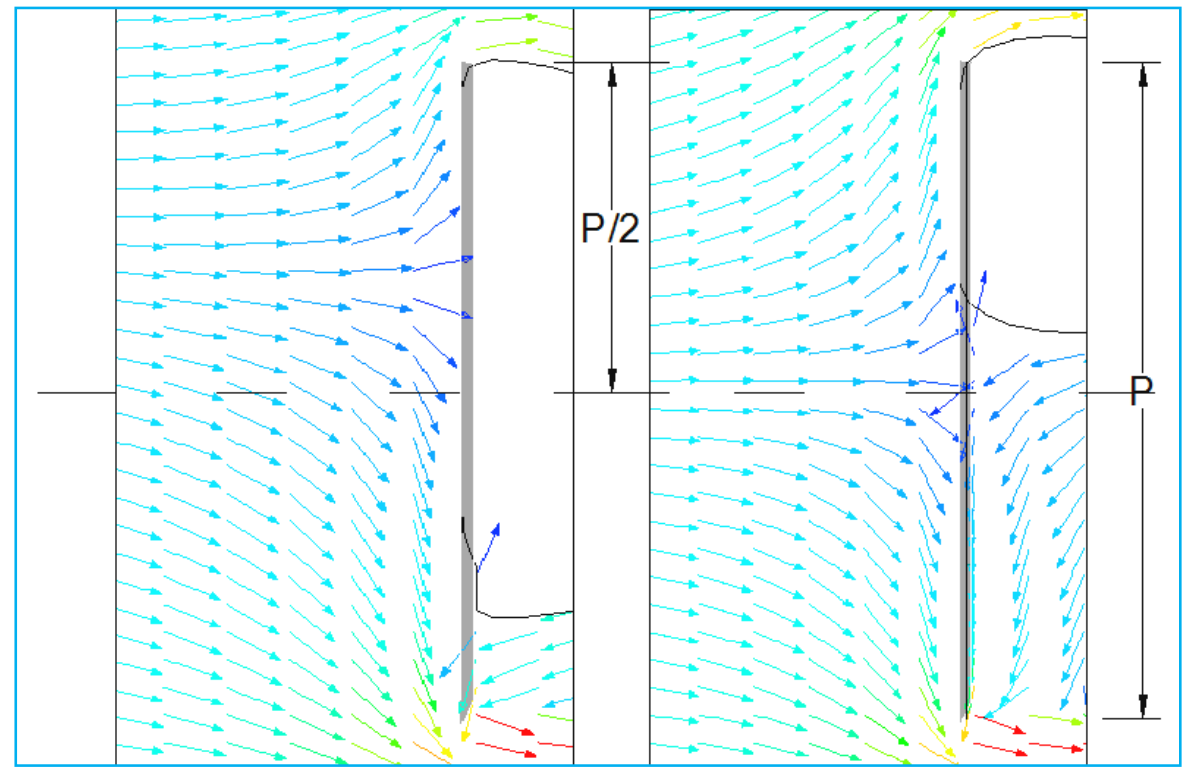

Figure (2) Visualisation of Flow Directions of Two Different Flow Rates for Constant (d)

As the directions of flow are affected by the head upstream, a different flow rate parts will stabilize. To illuminate the relationship of two flows with the total head upstream, two photo snaps are chosen to demonstrate how the directions of velocity vectors changes when they approach the solid obstacle. Figure (3) shows flow separation into two portions, the relative quantity between the portions depends on the depth of flow upstream. The increase of total discharge upstream and its depth will affect the relative flow portions of each weir and gate. The directions of velocity vectors can guide to notice that there is a relative increase in the upper portion which tends toward flowng over the weir as the depth of flow increases; this physical process is to fit the condition of weir flow so that more vectors have upward direction. Moreover figure (3) shows that the downstream gate flow condition also changes, it can be noticed that the submergence depth increases directly behind the gate due to the increase of the amount of water falling from the weir to the gate. This state of matter makes the head which causes the flow through gate variable and subordinate to balance state between upstream and downstream.

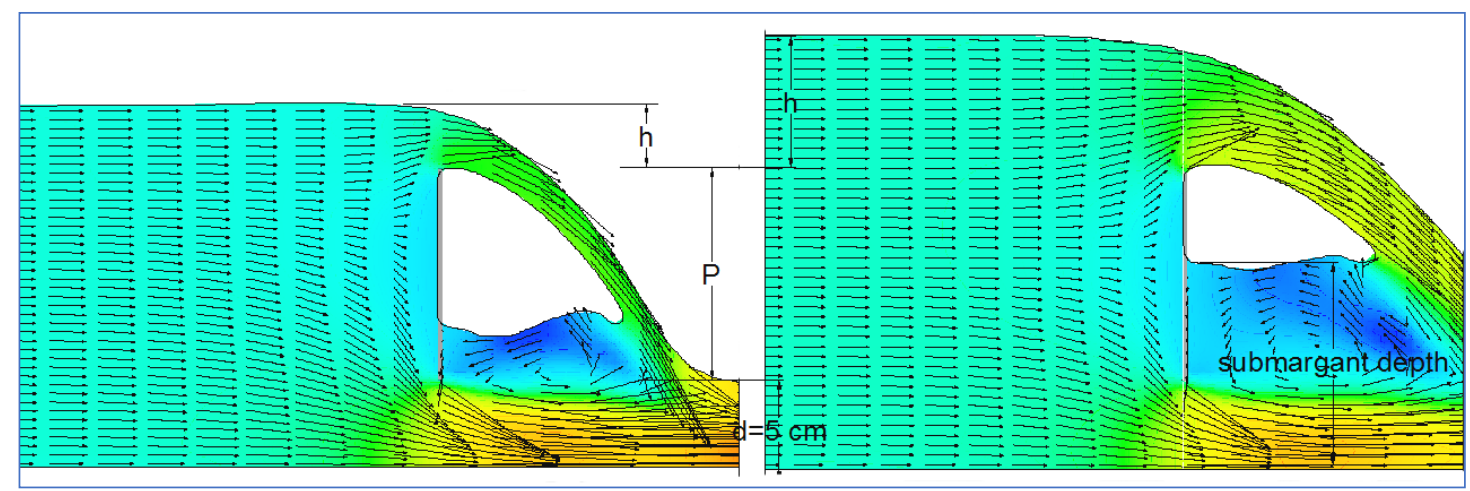

Figure (3) Visualisation of the Situation State of Two Flow Portions $d=5 \mathrm{~cm}$ 
The rate of flow upstream is the main variable. According to that rate a stagedischarge relationship is generated up due to existence of sharp-edged weirs and gates. The relative portions of flow is presented in figure (4), this figure shows, for constant gate opening, that the percentage of discharges weir to gate increases when there is an increase in Froude number $\left(\mathrm{Fr}_{1}\right)$.

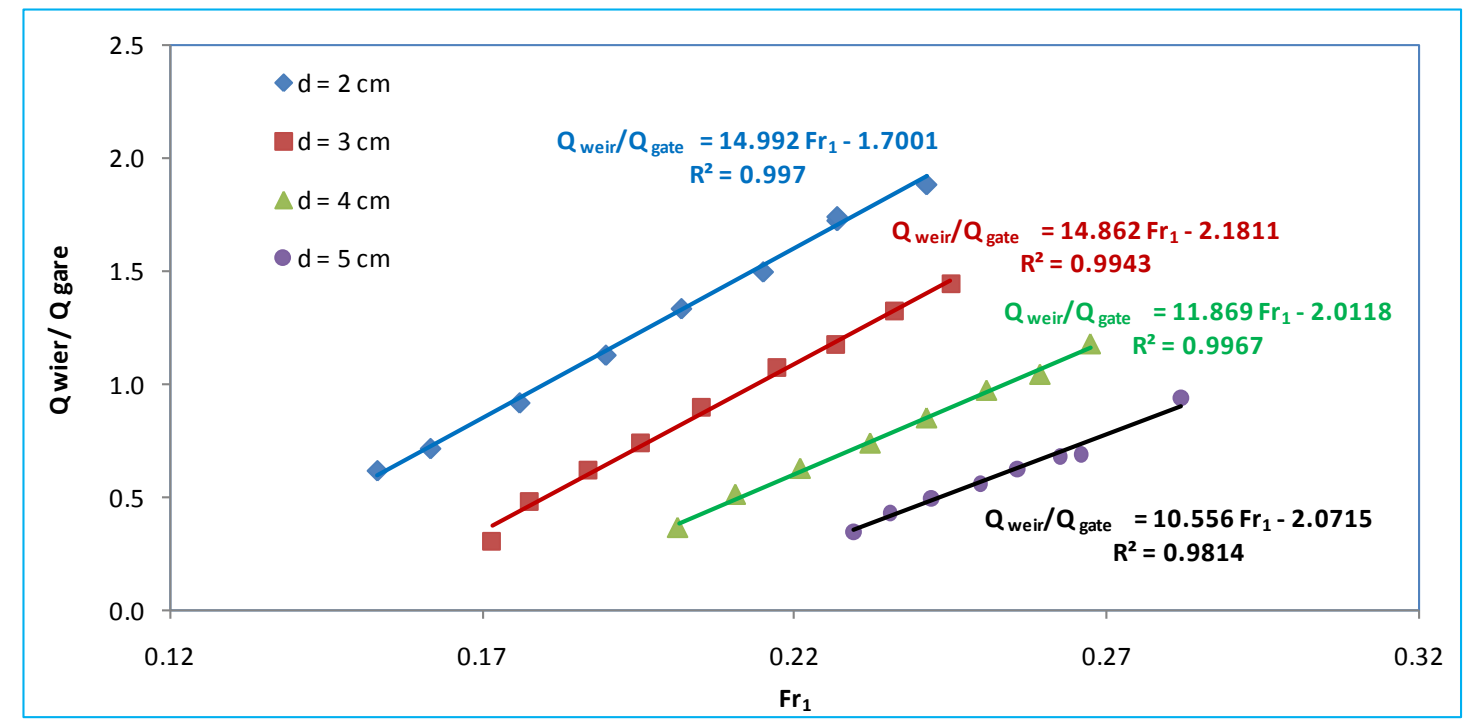

Figure (4) Relative Flow Discharges for Different Gate Openings Related to $\mathrm{Fr}_{1}$

The flow condition upstream is reflected by its depth $(\mathrm{H})$, so that the percentage of depth flow upstream to the gate opening $(\mathrm{H} / \mathrm{d})$ affects the the relative portions of flow. Figure (5) shows the percentage of ( $Q$ weir's /Q gate's) increase with the increases of $\mathrm{H} / \mathrm{d}$. Within the experimental limitations, the weir discharge increases from 0.4 up to 1.8 times gate discharge when the opening decreases by about $60 \%$. It was also found that when the total depth of flow upstream $(\mathrm{H})$ increases by $46 \%$. Accordingly the discharge of gate increases by 5\%,7\%,12\%, 26\% for the gate opening of 2, 3, 4, $5 \mathrm{~cm}$ respectively, while the weir dischage increases by about 5 times.

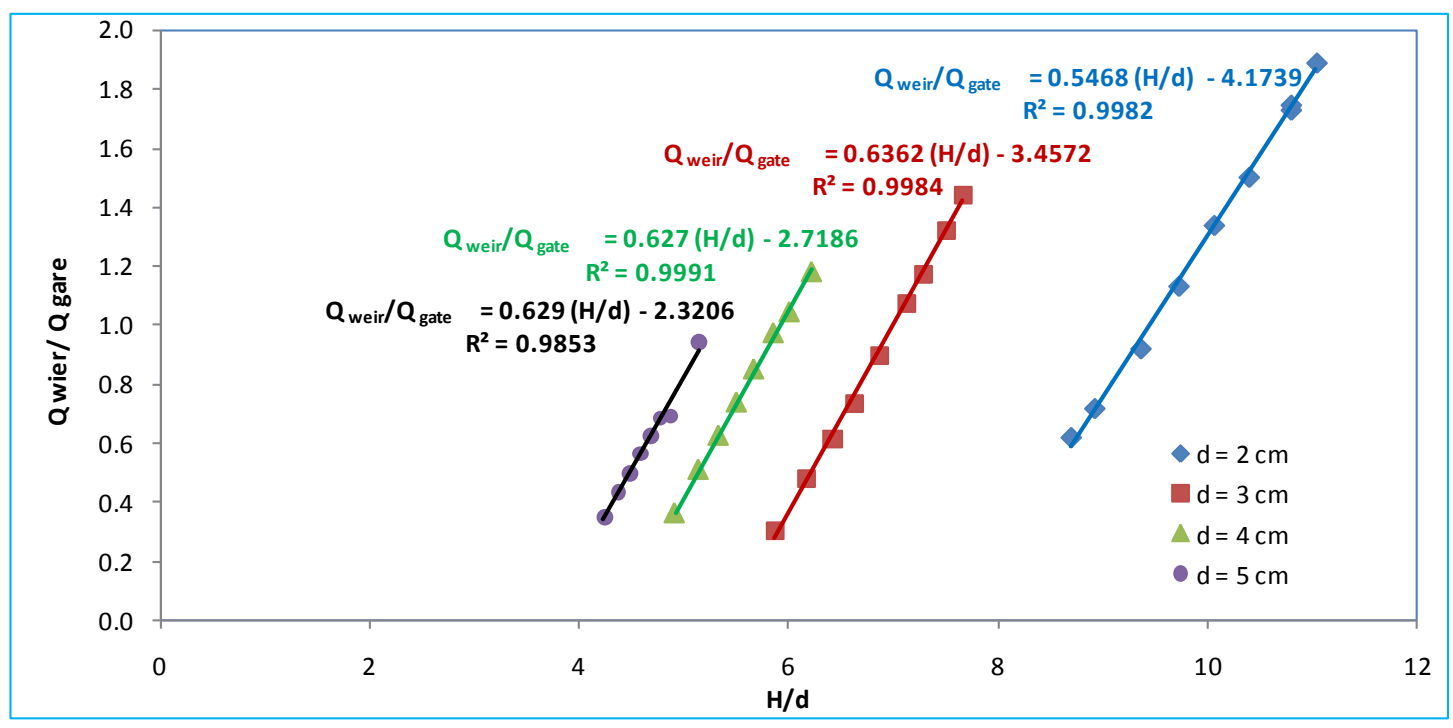

Figure (5) Variation of Relative Flow Discharges with H/d 
The discharge over a weir in combined system is not as it is in the traditional sharp weir. In the flow upstream, the system reacts in a different way to satisfy flow condition. The separation of flow starts early in two parts and the streamlines curvature are smoother in the weir portion flow there for, there is a less head loss and a better performance for the weir. Comparison is done between the discharge of sharp crested weir and that predicted by the model. The discharge of traditional weir is calculated based on Rehbock formula (1) for the corresponding experimental depth. The relative value from model prediction to the calculated one for the same head $(h)$ is presented in figure (6). It can be noted that the predicted weir discharge is higher than the calculated one and the percentage of relative values decreases as the depth of flow increases. This model is near to the real situation and so is its predicted discharge. This fact make a weir in combined system perform better by increasing the discharge from $5 \%$ to $20 \%$ for the same head (h).

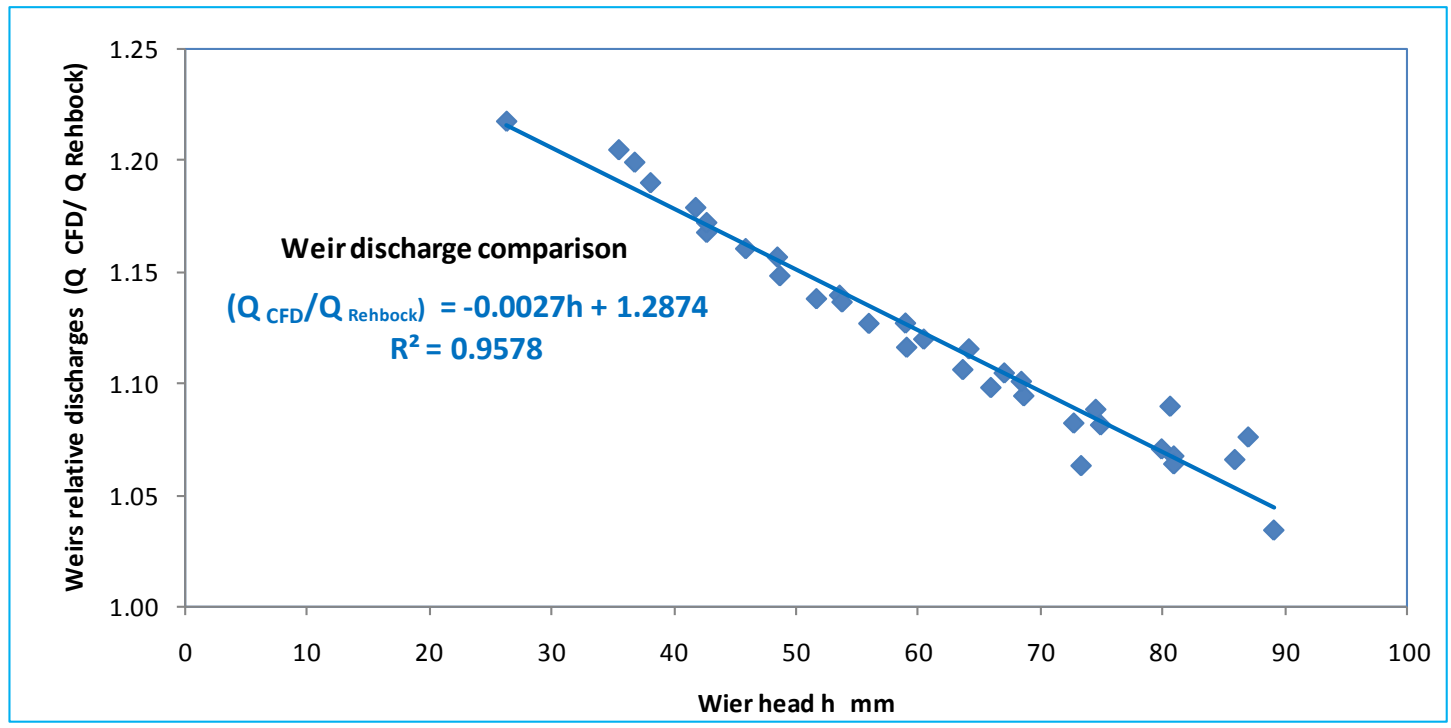

Figure (6) Comparison of Weir Discharge Predicted by Model and by Rehbock Formula.

The IBM-SPSS 20 Package is employed for correlating both weir discharge and gate discharge with the geometrical dimensionless $\mathrm{H} / \mathrm{d}$ and $\mathrm{h} / \mathrm{d}$. Significant correlation between variables of heigh Pearson correlation values at 0.01 levels (2-tailed) equal $0.840,0.629,0.632$ and 0.344 respectively. The statistical nonlinear regression is carried on to find a mathematical model for each of the two portions of discharge with the geometrical dimensionless parameters $\mathrm{H} / \mathrm{d}$ and $\mathrm{h} / \mathrm{d}$. The models show acceptable relationships which are listed in equations (9) and (10).

$$
\begin{aligned}
& Q_{\text {weir }}=24.072\left(\frac{h}{d}\right)^{0.535}-4.416\left(\frac{H}{d}\right)^{0.880}-0.214 \\
& \text { (9) } \quad R^{2}=0.958 \\
& Q_{\text {gate }}=5.475\left(\frac{h}{d}\right)^{0.707}-1225.168\left(\frac{H}{d}\right)^{0.014}+1261.689 \ldots(10) \quad R^{2}=0.918
\end{aligned}
$$


Journal of University of Babylon for Engineering Sciences, Vol. (26), No. (6): 2018.

\section{Conclusion}

In the combined flow system of weir and gate there is mutual effect. Within the study limitations, the results lead to the following findings:

1- The separation level of two flow portions falls dawn to reach $\mathrm{P} / 2$ as the flow depth (H) increases.

2- The weir discharge increases from 0.4 up to 1.8 times gate discharge as the gate opening decreases to $60 \%$.

3- As the upstream flow depth $(\mathrm{H})$ increases by $46 \%$, as the discharge of the four gate openings increases relatively by $5 \%, 7 \%, 12 \%, 26 \%$, while the weir discharge increase by about 5 times.

4- The weir in the combined system has a better performance; its discharge is higher by $5 \%$ to $20 \%$ for the same head (h) as compared with traditional one.

\section{References}

[1] Qu J., Ramamurthy A. S., and Tadayon Z.,Chen R., 2009. "Numerical simulation of sharp-crested weir flows", Can. J. Civ. Eng., vol. 36, no. 1971, pp. 1530-1534.

[2] Lv X., Zou Q., and Reeve D., 2011, "Numerical simulation of overflow at vertical weirs using a hybrid level set/VOF method", Adv. Water Resour., vol. 34, no. 10, pp. 1320-1334.

[3] Rady R. M. A. E., 2011, "2D-3D Modeling of Flow Over Sharp-Crested Weirs", J. Appl. Sci. Res., vol. 7, no. 12, pp. 2495-2505.

[4] Liu Y. L. and Bai Y. , 2012, "Simulation of a Free Surface Flow over a Vertical Weir", Appl. Mech. Mater., vol. 256-259, pp. 2616-2620.

[5] M. S. Akoz, V. Gumus, and M. S. Kirkgoz, Jun. 2014, "Numerical Simulation of Flow over a Semicylinder Weir", J. Irrig. Drain. Eng., vol. 140, no. 6, p. 4014016.

[6] Maghsoodi R., Roozgar M. S., Sarkardeh H., and Azamathulla H. M. , 2012, "3D-Simulation of Flow Over Submerged Weirs", Int. J. Model. Simul., vol. 32, no. 4, pp. 237-243.

[7] Sibson R. , 1980, "A vector identity for the dirichlet tessellation", Math. Proc. Cambridge Philos. Soc., vol. 87, no. 1, pp. 151-155.

[8] Daneshmand F., Javanmard S. A. S., Liaghat T., Moshksar M. M., and Adamowski J. F. , 2010, "Numerical solution for two-dimensional flow under sluice gates using the natural element method", Can. J. Civ. Eng., vol. 37, no. 12, pp. 1550-1559.

[9] Mohamed H. I., Abozeid G., and Shehata S. M. , 2010, "Hydraulics of clear and submerged overfall weirs with bottom circular-openings", Ain Shams Eng. J., vol. 1, no. 2, pp. 115-119.

[10] Saad N. Y. and Fattouh E. M. , 2017, "Hydraulic characteristics of flow over weirs with circular openings", Ain Shams Eng. J., vol. 8, no. 4, pp. 515-522. 
[11] Sadrabadi M. and moghaddam M. , 2016, "Numerical Simulation of flow patterns around Triangular porous weirs", in 10th International River Engineering Conference Shahid Chamran University, 19-21 Jan 2016, Ahwaz, no. Jan, pp. 1921.

[12] Altan-Sakarya A. B. and Kökpinar M. A. , 2013, "Computation of discharge for simultaneous flow over weirs and below gates (H-weirs) ", Flow Meas. Instrum., vol. 29, pp. 32-38.

[13] Khassaf S. I. and Habeeb M. , 2014, "Computation of discharge for simultaneous flow over weirs and below gates (H-weirs) ", Int. J. Sci. Eng. Res., vol. 5, no. 4, pp. 1-7.

[14] Samani J. M. and Mazaheri M. , 2009, "Combined Flow over Weir and under Gate", J. Hydraul. Eng., vol. 135, no. 3, pp. 224-227.

[15] Arvanaghi G., and Mahtabi H., 2014, "Hydraulic Characteristics of Rectangular Combined Sharp-Crest Weir-Gate", Adv. Environ. Biol., vol. 8, no. 21, pp. 32-38.

[16] Parsaie A., Haghiabi A. H., Saneie M., and Torabi H. , 2017, "Predication of discharge coefficient of cylindrical weir-gate using adaptive neuro fuzzy inference systems (ANFIS) ", Front. Struct. Civ. Eng., vol. 11, no. 1, pp. 111122.

[17] Henderson F. M. , 1966, Open Channel Flow. New York: Macmilan Pubishing co., Inc.

[18] Te Chow V. , 1959, Open-channel hydraulics. Tokyo: International Student Edition, Kogakusha Company, LTD.

[19] Subramanya K. , 2009, Flow in Open Channels, Third Edit. New Delhi: Tata McGraw-Hill.

[20] Lozano D., Mateos L., Merkley G. P., and Clemmens A. J. , 2009, "Field Calibration of Submerged Sluice Gates in Irrigation Canals", J. Irrig. Drain. Eng., vol. 135, no. 6, pp. 763-772.

[21] Defina A. and Susin F. M. , 2003, "Hysteretic behavior of the flow under a vertical sluice gate Hysteretic behavior of the flow under a vertical sluice gate", Phys. FLUIDS, vol. 15, no. 9, pp. 2541-2548.

[22] Versteeg H. K. and Malalasekera W. , 2007, An Introduction to Computational Fluid Dynamics, Second Edi. Edinburgh Gate: Pearson Education Limited England.

[23] Flow-3D 2012, Flow-3D Documentation, Release 10.1.0. 


\section{تحليل مخرجات المحاكاة للتأثير المتبادل للتدفق في نظام مشترك هدار ويوابة سرحان عبد الستار شاكر عبد اللطيف جليل قسم هندسة الدوارد المائية، كلية الهندسة، جامعة دهوك، العراق sarhan.abdulsatar@uod.ac $\quad$ shaker.abdulatif@uod.ac} الخـــلاصة يمكن الحد من مشكلة المواد المعلقة وترسبها بإستخدام نظام جريان مشترك يتكون من هدار وبوابة.

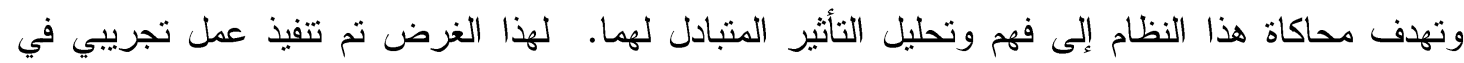

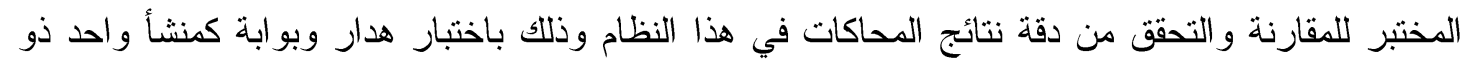
حواف حادة وبتغيير ارتفاع البوابة لأربع مرات وتسجيل مناسيب السطح وقيم التصريف. أجريت عمليات المحاكاة بالاعتماد على النموذج ع - RNG k للاضطرابات وقد أظهرت مقارنة السطح الحر للجريان

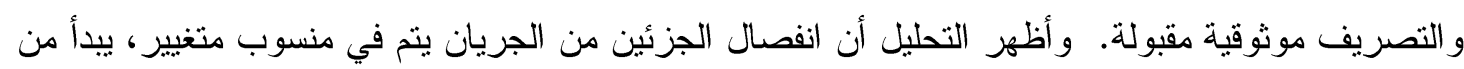
منسوب أقرب لحافة الهدار في التصاريف المنخفضة ثم يبتعد نحو الاسفل ليصل نصف المسافة بين الحافتين تقريبا عند ارتفاع عمق الماء أعالي المنشأ. وتزداد نسبة تصريف الهدار الى تصريف البوابة من 0.4 إلى لى 1.8 عند تقليل فتحة البوابة الى نسبة 60٪ بالنسب 5\%، 7\%، 12\%، 12 26فتحات بوابة 2، 3، 4، 5 سم على التو الي في حين أن تصريف الهدار يزداد

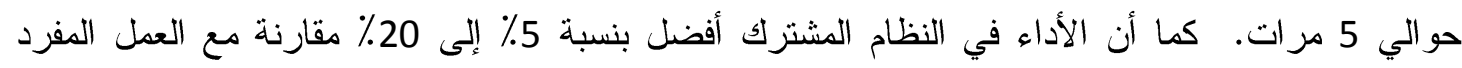

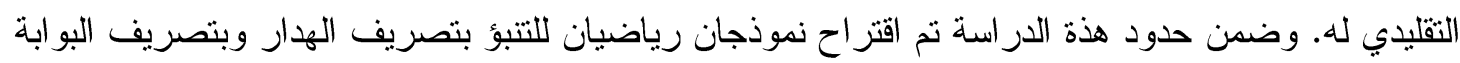

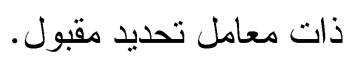
الكلمات المفتاحية: نظام مشترك؛ تدفق الهدار ؛ تدفق البو ابة؛ أجز اء التدفق؛ فتحة البو ابة. 